\title{
The Management of Left Pulmonary Artery Sling in Senegal: Our Experience from One Case
}

Mohamed Leye ${ }^{1}$, IdrissaDemba $\mathrm{Ba}^{2}$, Ababacar Mbengue ${ }^{3}$, Adama Sawadogo ${ }^{4}$, Fatou $\mathrm{Aw}^{5}$,

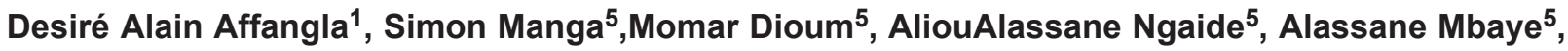
Modibo Doumbia ${ }^{4}$, Djibril Marie $\mathrm{Ba}^{1}$, Rosette Godonou ${ }^{1}$, Ibrahima Bara Diop ${ }^{5}$

${ }^{1}$ Department of Cardiology, Unit of Training and research in medical sciences, University of Thies,

${ }^{2}$ Department of Pediatric Pneumology, Hôpitald'enfants Albert ROYER, ${ }^{3}$ Department of Radiology, Hôpital Principal de Dakar, ${ }^{4}$ Department of Cardiovascular and Thoracic Surgery, Cheikh Anta DIOP University, Dakar, ${ }^{5}$ Department of cardiology, Cheikh Anta DIOP University, Dakar

\begin{abstract}
:
Keywords: $\quad$ Pulmonary Artery Sling (PAS) is a rare congenital heart disease due to abnormal origin of Left Pulmonary artery, Pulmonary Artery (LPA) from the Right Pulmonary Artery (RPA), then encircling the distal part of Vascular ring, the trachea. The treatment is a surgical repair consisting of reimplantation of the LPA on the main Congenital heart pulmonary artery over cardiopulmonary bypass. The authors report a clinical case of PAS in a 5.5 disease, Trachea. $\quad$ years old boy diagnosed in Senegal then successfully operated in France.
\end{abstract}

(Cardiovasc. j. 2017; 10(1): 94-96)

\section{Introduction:}

Pulmonary artery sling is a rare congenital heart disease in which the LPA is originating from the RPA then encircling the distal trachea and the right main bronchus. ${ }^{1}$ This is a malformation that is often revealed while investigating respiratory distress and congenital heart disease in infants. The respiratory signs are not specific and may include wheezing, stridor, dyspnea on effort, coughing and recurrent infections of lower airways. ${ }^{2}$ In ideal situation, ${ }^{3}$ the diagnosis is made by echocardiogram while the bronchoscopy accesses the bronchial stenosis. The treatment is strictly surgical and classically consists of cutting the LPA then reimplanting it on the pulmonary artery (PA) main stem by sternotomy and cardiopulmonary bypass (CPB). Tracheal repair is indicated if the patient is clinically symptomatic. We report a case of PAS in a 5.5 years old boy diagnosed in the Department of Cardiology of the University Hospital of Fann Dakar then successfully repaired in Monaco.

\section{Case report:}

$\mathrm{AD}$, a boy of 5.5 years old was admitted for dyspnea with stridor occurring on exercise. There was no dizziness, sweating or cyanosis. On the previous medical history, a recurring bronchitis is reported but there was no consanguinity and the pregnancy was followed up to deliverance. He was hospitalized twice at the ages of 2 months old and 3.5 months old respectively for dyspnea and stridor that were treated by salbutamol puff and physiotherapy. The physical examination showed a good growth regarding the weight $(21 \mathrm{Kg})$ and height $(121 \mathrm{~cm})$ which were corresponding to $\mathrm{Z}$ score -0.94 . The cardiovascular examination was normal with oxygen saturation at $98 \%$. The respiratory examination showed suprasternal retraction and expiratory wheezing. There were no abnormal findings in the liver, ENT and dental areas. On the chest $\mathrm{X}$ rays, cardiac outline, pulmonary

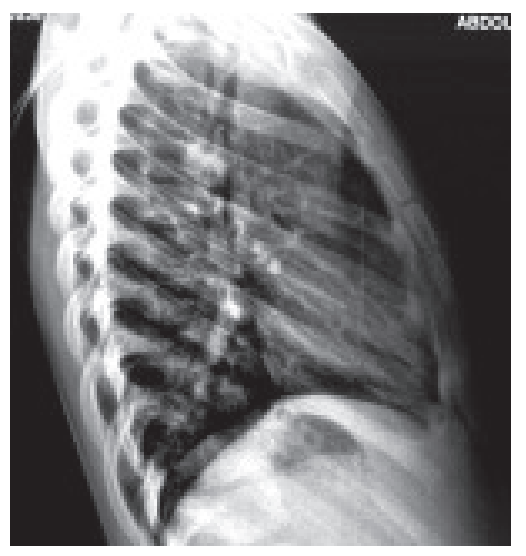

Fig.-1: Lateral view of chest X ray.

Address of Correspondence: Dr. AdamaSawadogo,Department of Cardiovascular and Thoracic Surgery, Cheikh Anta DIOP University, Dakar, Senegal. Email: adamsaw2000@yahoo.fr 
parenchyma, vessels, and pleura were normal. On the lateral view (figure 1) it was difficult to spot a tracheal stenosis as it was not quite penetrated.

The echocardiogram found situs solitus levocardia and good size of cardiac chambers. The cardiac function was good and the aortic arch was also normal, left-sided and free of abnormality. There was no coarctationor interrupted aorta. The PA stem had a good size with a normal RPA but the LPA was not well detected. On the angio CT, the LPA had a retro tracheal tract with a severe stenosis on the tracheal segment followed by a normal size (Fig 2). The PA stem and the RPA were normal and there was no significant tracheal stenosis. The lab tests were normal.

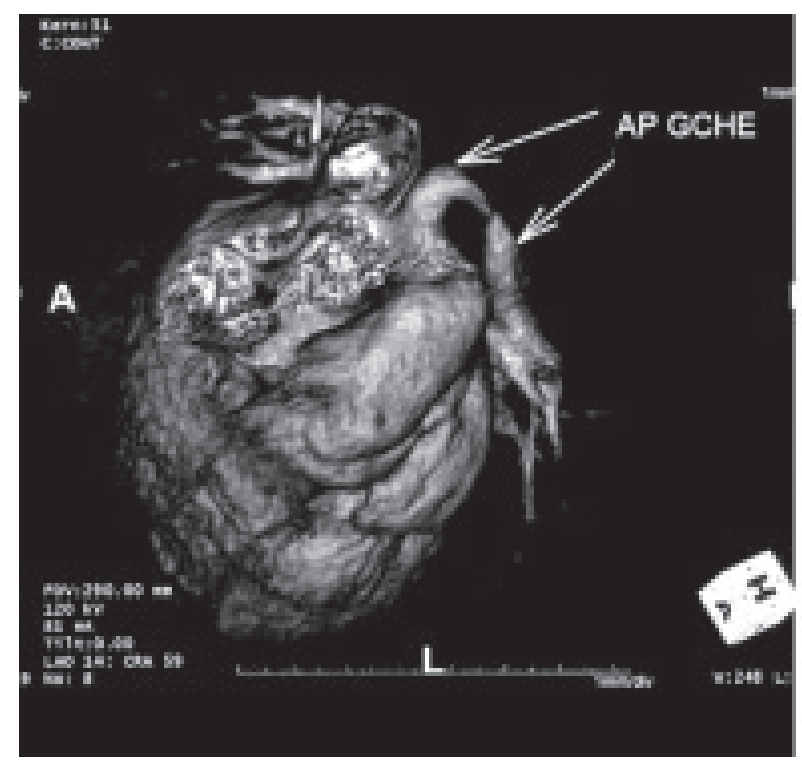

We indicated a surgical repair and $\mathrm{AD}$ was transferred to the cardiothoracic centre of Monaco where he underwent reimplantation of the the LPA over CPB and beating heart. LPA was cut at its origin, running suture of the stump and switch of the LPA from the bronchus. Then the LPA was shortened and reimplanted on the main PA. The CPB duration was 29 minutes. The postoperative echocardiogram (Fig3) showed good function of both right and left ventricles and no obstacles on theirs outputs tracts. The RPA was seen in a position just little far than usual but there was no tricuspid regurgitation and the atrial septal was normally curved. The postoperative course was simple and the patient discharged from hospital at day 7 .

Fig.-2: Chest CT scan: retro tracheal LPAvisibletracheal stenosis

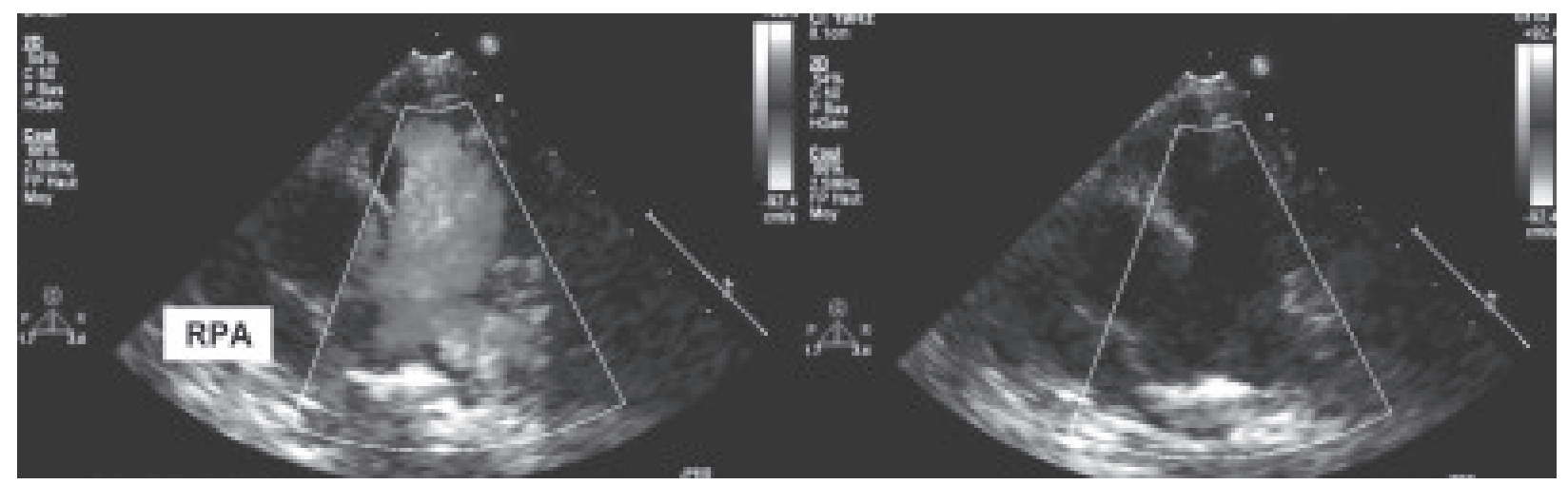

Fig.-3: Post operative echocardiography (flow going from the MPA to the LPA andthe origin of RPA. No aliasing.) 


\section{Discussion:}

Retro tracheal LPA is a rare congenital malformation that happens at the $5^{\text {th }}$ week of pregnancy and that represents about $3 \%$ of the etiologies of extrinsic tracheal stenosis according to Landing. ${ }^{4}$ In the literature, the PAS is often described as asymptomatic during childhood. Nevertheless when the parents of patients are further interviewed, they report some signs. These may include dyspnea, coughing, wheezing, stridor and limitation of exercise. ${ }^{2,3,5,6}$ Likewise our patient, the male sex was predominant in many studies such as the series of $\mathrm{Yu}$ and Gikonyo who reported $72 \%$ and $60 \%$ of male patients respectively. ${ }^{2,5}$ Although there are 3 theories to explain this vascular malformation, none is unanimous. The first one state it is a total absence of development of the LPA and the blood supply comes from the RPA. For the $2^{\text {nd }}$ theory it is rather an anomalous implantation of the LPA and the primitive vascular pedicle of lung. The last and most recent theory claims it is a persisting connection between the primitive pulmonary vascular pedicles. All of these theories are accepted and each is validated depending on the type of implantation of the LPA. ${ }^{7}$ Diagnosis is usually confirmed by CT scan and RMN that show both anomalous PA and tracheal compression; bronchoscopy is useful to assess respiratory tract. ${ }^{8}$

Once the diagnosis is made, the treatment is a surgical repair. For our patient a reimplantation of the LPA by median sternotomy over CPB without cardioplegia was performed. No tracheal repair was performed. Indeed median sternotomy is the classical approach to getting to the heart in many series. Left thoracotomy is another alternative. For instance regarding the surgical approach, Barker et al. ${ }^{9}$ have reported $67 \%$ of median sternotomy and $33 \%$ of thoracotomy in a series of 24 children operated for PAS. The main reason is that sternotomy makes easier the CPB and allow a good access to the PA and its branches in their intra pericardial part. Tracheal repair is only indicated in case of significant tracheal stenosis. ${ }^{10}$ The operative time varies depending on association with other malformations or not. The immediate post-operative course was good allowing hospital discharge after a week. Most of authors emphasize the low rate of morbidity and mortality for PAS. ${ }^{4,6,9}$ To illustrate, in the series of Young, no death was noticed in 9 cases of LPA reimplantation for PAS. ${ }^{10}$

\section{Conclusion}

Because of the no-specific signs of pulmonary artery sling and its rarity, this malformation is often not diagnosed at the clinical assessment. Since cardiopulmonary bypass is used, morbidity related to reimplantation of left pulmonary artery to correct the condition has been significantly decreased.

Conflict of interest: Authors acknowledge no conflict of interest in the submission.

Disclosures: Authors have nothing to disclose with regard to commercial support.

\section{References:}

1. Potts WJ, Holinger PH, Rosenblum AH. Anomalousleft pulmonary artery causing obstructionto right main bronchus: report of a case. J Am Med Assoc 1954;155(16):1409-1411.

2. Yu J-M, Liao C-P, Ge S, Weng ZC, Hsiung M-C, Chang $\mathrm{J}-\mathrm{K}$, et al. The prevalence and clinical impact of pulmonary artery sling on school-aged children: a largescale screening study. Pediatr Pulmonol 2008; 43(7):656-661.

3. Hraska V, Photiadis J, Haun C, Schindler E, Schneider M, Murin P, et al. Pulmonary artery sling with tracheal stenosis. Multimed Man Cardiothoracic Surg 2008; doi:10.1510/mmcts.2008.003343.

4. Landing BH. Congenital malformations and genetic disorders of the respiratory tract (Larynx, trachea, bronchi, and lungs). Am Rev Respir Dis 1979; 120: 151-177.

5. Gikonyo BM, Jue KL, Edwards JE. Pulmonary vascular sling: report of seven cases and review of the literature. Pediatr Cardiol 1989; 10:81-89.

6. Healey D, Ron N, Hromada A, and Chhabra M. Perinatal /Neonatal case presentation: pulmonary artery sling associated with respiratory distress. Springer Plus 2016; 5(31):1-4.

7. Carfagna L, Boualib O, Galinier P, Vayssea P, Moscovici $J$, Guitard J, et al. Artère pulmonaire gauche rétrotrachéale : mise au point embryologique et anatomique. Morphologie 2009; 93 : 30-34.

8. Delacour D, Demeyere M, Dubourg B, Dacher JN. Left pulmonary artery sling: A rare cause of congenital stridor. Diagn Interv Imaging 2016; $3: 1-3$.

9. Backer CL, Mavroudis C, Dunham ME, Holinger LD. Pulmonary artery sling: results with median sternotomy, cardiopulmonary bypass, and reimplantation. Ann Thorac Surg 1999; 67: 1738-1745.

10. Yong MS, D'Udekem Y, Brizard CP, Robertson T, Robertson CF, Weintraub R, et al. Surgical management of pulmonary artery sling in children. $J$ Thorac Cardiovasc Surg 2013; 145(4):1033-1039. 